\title{
Preparation of Ink-Jet Inks with Quinizarin as "Antifraud Marker" for Textile Digital Printing
}

E. K. Karanikas*, N. F. Nikolaidis

Department of Industrial Chemistry and Chemical Technology, School of Chemistry, Aristotle University of Thessaloniki, GR54124, Thessaloniki, Greece

Article History
Received: 02.11 .2020
Accepted: 13.11 .2020
Published: 17.11 .2020
Journal homepage:
https://www.easpublisher.com/easjecs
Quick Response Code

\begin{abstract}
Quinizarin, an anthraquinone derivative, was used as "antifraud marker". It was added in three several amounts $(0.25 \%, 0.5 \%$ and $1.0 \%)$ in water-based disperse ink-jet inks. Surface tension, viscosity, conductivity and $\mathrm{pH}$ of the ink formulations were monitored over a period of 90 days in order to estimate the ink stability and the compatibility of the "antifraud" active agents with the ink constituents. The inks were used for ink-jet printing to polyester and polyamide samples. Fastness (light, wash and rub) and also color properties of the samples were measured. Finally, qualitative and quantitative determination of the active agent was made from the printed samples with extraction.
\end{abstract} Keywords: Anti-fraud markers, digital printing, disperse dyes, ink-jet inks, Quinizarin.

Copyright (C) 2020 The Author(s): This is an open-access article distributed under the terms of the Creative Commons Attribution 4.0 International License (CC BY-NC 4.0) which permits unrestricted use, distribution, and reproduction in any medium for non-commercial use provided the original author and source are credited.

\section{INTRODUCTION}

Ink jet printing is one of the fastest growing of imaging technologies; compared to conventional printing methods, ink jet printing generates lower waste and uses lower amounts of energy and water [1-3].

Ink jet inks must be carefully formulated to yield specific properties that enable optimum droplet formation within the fine nozzles of a printing head for application at high speed. Such properties are dependent upon the $\mathrm{pH}$, surface tension, viscosity, conductivity and particle size distribution of the ink. Furthermore, inks designed for the ink-jet printing of textile materials need to satisfy various fastness criteria namely wash, light and rubbing [2-4].

Water-based ink-jet inks offer environmental advantages over their non-aqueous based counterparts, through reduced emissions of volatile organic compounds that are otherwise present in solvent-based formulations. With environmental considerations continuing to have ever-greater impact upon industry and legislation, textile producers have to carefully examine the environmental impact of the products used. Water-based inks contain, typically, 30-80\% water as a proportion of the total mass of the ink, together with a water miscible organic solvent such as a monohydric alcohol (methanol, ethanol, isopropanol), the colorant (e.g. disperse dye) and a surface active agent which, in the case of disperse dyes, acts as a dispersant for the dye in the aqueous medium [4-5].

The increasing use of CAD systems, with the consequent ability to store patterns in digital form, makes it particularly attractive [6]. Additionally, the use of electronic method of carrying out the printing operation and thereby eliminate the costly and timeconsuming process of screen-making is of great importance in terms of drastically reducing the production cost [7]. With the increased pressure from developing textile markets in the Far East, the textile printer in Europe, Japan and the USA must respond with both increased quality and shorter response time. This means supplying new design concepts, sample and production of printed fabrics in a wide range of color ways in a time frame unheard of a few years ago and with substantially reduced production cost.

Conventional printing is growing in the Far East and is declining in the developed Western printing markets whereas digital textile printing is growing fast in the old established developed textile markets such as of Europe, Japan and USA [8]. 
Since 1991, digital textile printing systems have been available that can be used for proofing and small sample production. A considerable number of major research projects (Europe, Japan, USA) aimed at taking digital textile printing to full production scale [9].

It is common to everyone that developed countries are flooded with cheap low quality counterfeit products which try to copy well established brand names. This occurs for all industrial products from garments, textiles and household items, to electric appliances etc. The competition is unfair because years of research and development to market new products, new designs and fashionable items are wasted along with huge financial loss due to dramatic drop of sales. This has a catastrophic influence in the industry in the economies of the developed countries leading to higher unemployment and factory closures.

Many organic compounds have been used conventionally as antifraud tracers and markers.1,4Dihydroxyanthraquinone, commercially named Quinizarin or Solvent Orange 86, is an organic compound derived from anthroquinone. Quinizarin is an orange or red-brown crystalline powder. It is formally derived from anthraquinone by replacement of two hydrogen atoms by hydroxyl $(\mathrm{OH})$ groups. It is one of ten dihydroxyanthraquinone isomers and occurs in small amounts (as a glycoside) in the root of the madder plant, Rubia tinctorum [10]. Quinizarin is an inexpensive dye that is used to color gasoline and some heating oils. It is used as an intermediate for the synthesis of indanthrene- and alizarin-derived dyes. The $\mathrm{OH}$ groups can be replaced by chloride. Chlorination and bromination afford other dyes. Amination (replacement of one $\mathrm{OH}$ by $\mathrm{ArNH}$ ) with aniline derivatives followed by sulfonation affords other dyes such as Acid Violet 43. It is also used to form lake pigments with calcium, barium, and lead [11].

The present research work aims to develop an easy to use "antifraud digital printing system" to distinguish the original from the counterfeit items. The "antifraud digital printing" ideally should be able to print on a variety of substrates such as natural and synthetic textiles, paper and packaging material, glass etc. The "antifraud digitally printed" material will be easily distinguished from the counterfeit printed product. Quinizarin was used as antifraud marker (Figure-1). Three different amounts of Solvent Orange 86 were added in the water-based disperse ink-jet inks prepared. The inks were used for ink-jet printing of polyester and polyamide samples. Fastness and color properties of the samples were measured. Qualitative and quantitative determination of Quinizarin desorbed from the printed samples was made and a simple spectrophotometrical method for their detection was proposed.

\section{Experimental SeCtion Materials}

Double-Jersey $100 \%$ polyester fabric white $190 \mathrm{~g} / \mathrm{m}^{2}$ supplied by Grenter-Jersey AG (Switzerland) as well as nylon 6.6 (78F46, $1.69 \mathrm{dtexpf)}$ supplied by KYKE HELLAS were used. Commercial samples of C.I Disperse Blue 60 (Serilene Brilliant Blue 2GN) were kindly supplied by Yorkshire Colours, Germany (Figure 1). Commercial grade 2-propanol (Fluka) and ethylene glycol (Riedel-de-Haen, Germany) were used. Alcoospers LFD (KYKE HELLAS SA) a condensation product of formaldehyde-sulphonic acid sodium salt was used as dispersing agent. Anthroquinone derivative Quinizarin (Solvent Orange 86) (KYKE HELLAS SA) was used as antifraud tracer (Figure-1).

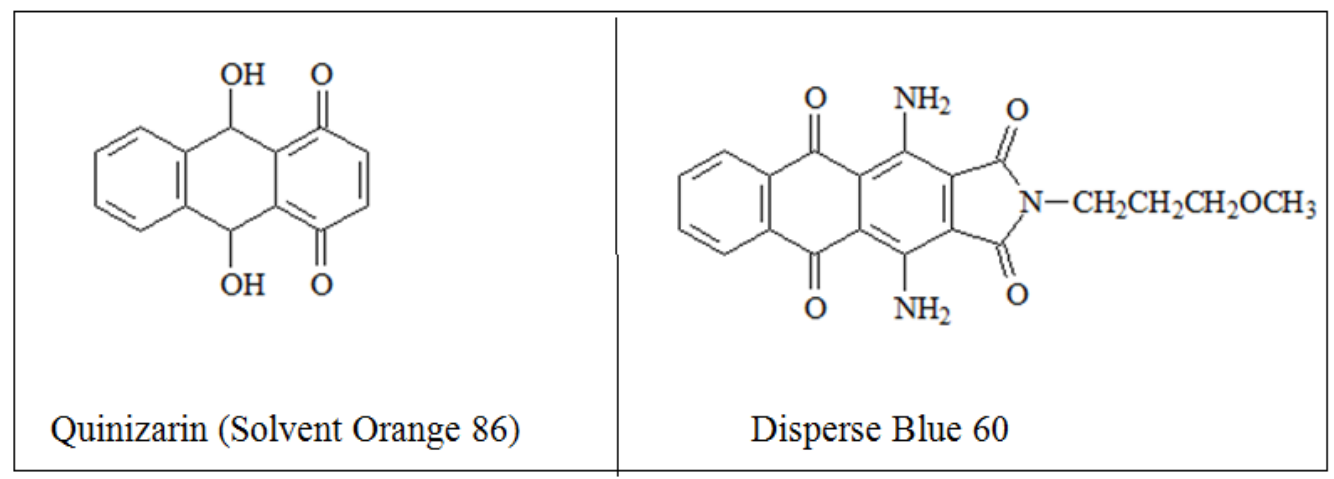

Fig-1: The active agent and the Dye used

\section{Ink Formulation}

In Table-1 the water-based ink formulations containing $2 \% \mathrm{w} / \mathrm{v}$ dye, $75 \% \mathrm{v} / \mathrm{v}_{2} \mathrm{O}$, a mixture of 2propanol (IPA)/ethylene glycol (EG) $20 / 5 \mathrm{v} / \mathrm{v}$ as the miscible solvent, $0.05 \% \mathrm{w} / \mathrm{v}$ dispersing agent $[12,13]$ and various \% amounts of solution $0.25 \%$ w/v Quinizarin in solvent butoxy ethanol, as active agent are given. The reference formulations without the inclusion of the active agent are also included. 
Table-1: Disperse ink formulations

\begin{tabular}{|l|l|l|l|l|l|l|}
\hline Formulation & $\begin{array}{l}\text { Dye/ } \\
\boldsymbol{\%}(\mathbf{w} / \mathbf{v})\end{array}$ & $\begin{array}{l}\mathbf{H}_{\mathbf{2}} \mathbf{O} / \\
\boldsymbol{\%}(\mathbf{v} / \mathbf{v})\end{array}$ & $\begin{array}{l}\text { IPA/ } \\
\boldsymbol{\%}(\mathbf{v} / \mathbf{v})\end{array}$ & $\begin{array}{l}\text { EG/ } \\
\boldsymbol{\%}(\mathbf{v} / \mathbf{v})\end{array}$ & Alcoospers/\%(w/v) & $\begin{array}{l}\mathbf{0 . 2 5 \%} \text { Quinizarin(w/v)/ } \\
\boldsymbol{\%}(\mathbf{v} / \mathbf{v})\end{array}$ \\
\hline 1.1 & 2 & 75 & 20 & 5 & 0.05 & - \\
\hline 1.2 & 2 & 75 & 20 & 5 & 0.05 & 0.25 \\
\hline 1.3 & 2 & 75 & 20 & 5 & 0.05 & 0.5 \\
\hline 1.4 & 2 & 75 & 20 & 5 & 0.05 & 1.0 \\
\hline
\end{tabular}

The mixture of ingredients was homogenized for $10 \mathrm{~min}$ using a Sonicator UP50H (Hilscher) homogenizer at room temperature.

Surface tension, conductivity, viscosity and $\mathrm{pH}$ measurements

Surface tension measurements were made using a KSV Sigma 70 tensiometer fitted with a De Nouy platinum ring. Conductivity measurements were performed using a Crison Conductimeter Basic 30 and pH measurements were made using a WTW Microprocessor $535 \mathrm{pH}$ meter; viscosity measurements were made using a Viscostar plus+ $\mathrm{H}$ (Fungilab) viscometer. The above properties were measured at room temperature and atmospheric pressure for $1,7,14$, 28, 60, 90 days for the inks with and without active agent.

\section{Ink-Jet Printing}

Printing was performed on paper, with printer Canon iP7250, followed by transfer printing on paper and then transfer and thermostabilization at $190^{\circ} \mathrm{C}$ to polyester and polyamide fabric for $30 \mathrm{sec}$.

The printed samples were then rinsed in cold water and reduction cleared using a solution comprising $2 \mathrm{~g} / \mathrm{l}$ sodium dithionite and $1.5 \mathrm{~g} / \mathrm{l}$ sodium carbonate at $60^{\circ} \mathrm{C}$ using a liquor ratio of $20: 1$ for $20 \mathrm{~min}$. The reduction cleared samples were rinsed in water and allowed to dry in the open air.

\section{Fastness Tests}

The fastness of polyester and polyamide prints were carried out according to ISO $105 \mathrm{C02}$ (washing), ISO 105 B02 (light) and ISO 105 X12 (rubbing) [12].

\section{Color measurements}

The reflectance values of the prints were measured using a Macbeth CE 3000 spectrometer under D65 illumination, $10^{\circ}$ standard observer with UV included and specular component excluded. The CIE $\mathrm{L} * \mathrm{a} * \mathrm{~b} * \mathrm{C} * \mathrm{H} *$ coordinates and the $\mathrm{K} / \mathrm{S}$ values were calculated from the reflectance values at the appropriate $\lambda \max (680 \mathrm{~nm}$ in case of Disperse Blue 60).

Identification and quantitative determination of the active agent adsorbed on printed polyester and polyamide samples

Quantitative determination of the active agent on the printed sample was made after extraction of Quinizarin with a mixture of cresol/heavy naftha 50/50 $\mathrm{v} / \mathrm{v}$ as the extract solvent, and measuring spectrophotometrically the extract at $483.5 \mathrm{~nm}$ ( $\lambda$ max of Solvent Orange). One extraction cycle $(0.4 \mathrm{~g}$ sample in a liquor ratio $1: 25,30 \mathrm{~min}$, at room temperature for both polyester and polyamide) were carried out for the quantitative recovery of Quinizarin from the printed polyester and polyamide fabrics. Figure 2 and 3 show the spectrum of Quinizarin (Solvent Dye 86) and Disperse Blue 60.

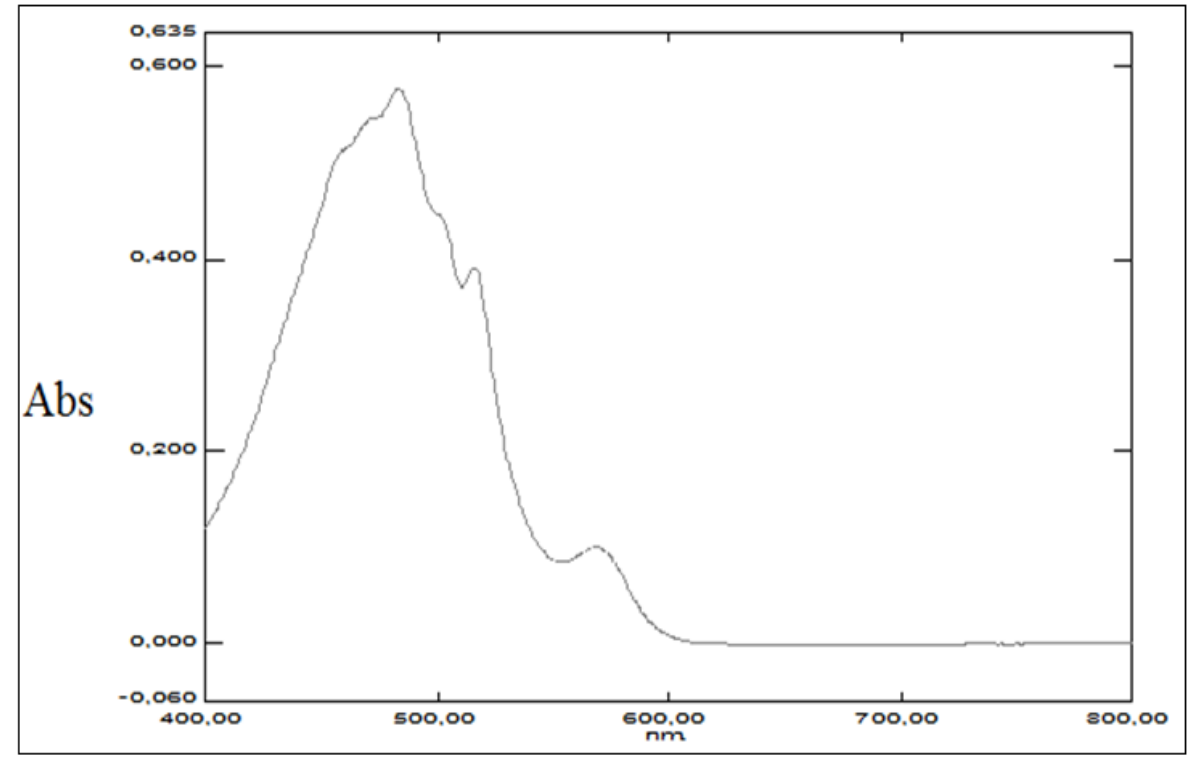

Fig-2: The spectrum of Solvent Orange 86 used 


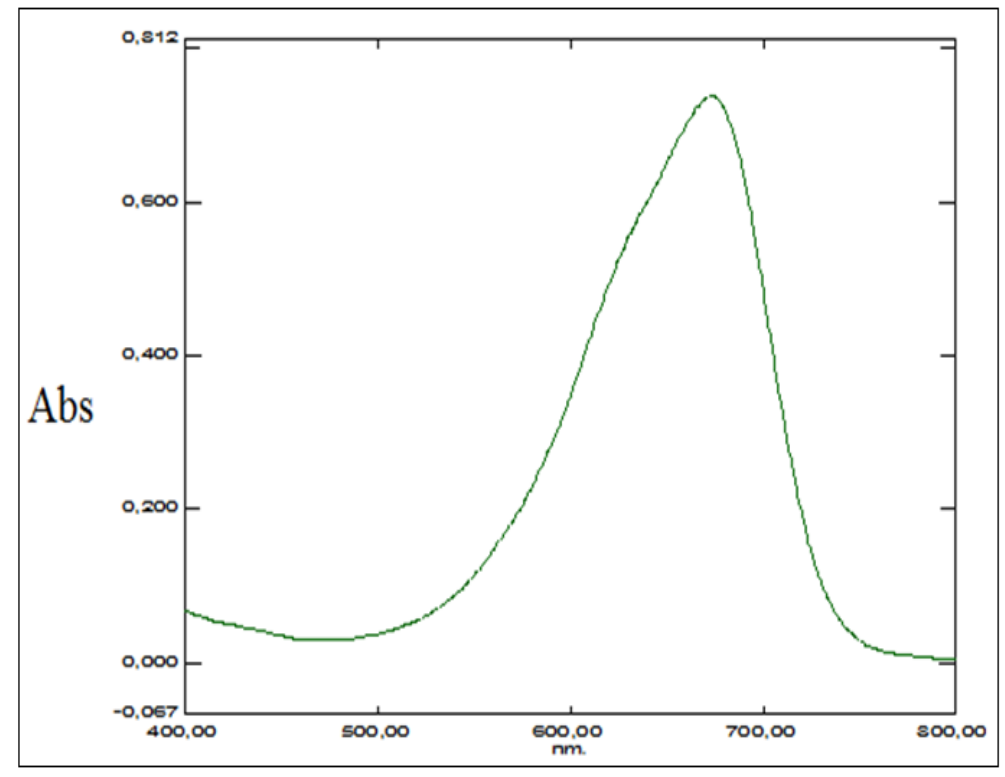

Fig-3: The spectrum of Disperse Blue 60 used

\section{RESUlTS AND DisCUSSION}

\section{Ink Properties Measurement}

Three water-based ink-jet inks with dye Disperse blue 60 containing quinizarin as antifraud marker were prepared (Table-1). One reference ink-jet ink (without antifraud agent) was also prepared. Monitoring a formulation over a period of time is a widely accepted method for evaluating dispersion stability $[4,8,13]$. In this study the surface tension, $\mathrm{pH}$, viscosity and conductivity of the formulations prepared were monitored over a period of 90 days.

\section{pH Measurement}

Figure-2 shows the $\mathrm{pH}$ values of the inks prepared with and without the active agent against time of storage. From above figures it can be concluded that all formulations have generally low values $\mathrm{pH}$ (5.98-5) followed by small decrease over the period of storage time. This is due to the fact that the blue dye has been milled and processed in low $\mathrm{pH}$. The addition of the antifraud agent in the blue dye formulation results in a $\mathrm{pH}$ decrease in all cases compared to the reference formulation (without antifraud agent). This can be explained by the fact that the solution of quinazarin has acid $\mathrm{pH}$ in the region of 4.5- 5 due to its phenolic character and when added to the blue formulation inks causes a slightly drop in the $\mathrm{pH}$ of the resulting formulation. Given that acceptable $\mathrm{pH}$ values for ink-jet inks are near the neutral region $(6.5-8)[14,15]$ all the blue formulations with and without the active agent need a slightly correction with a buffer solution.

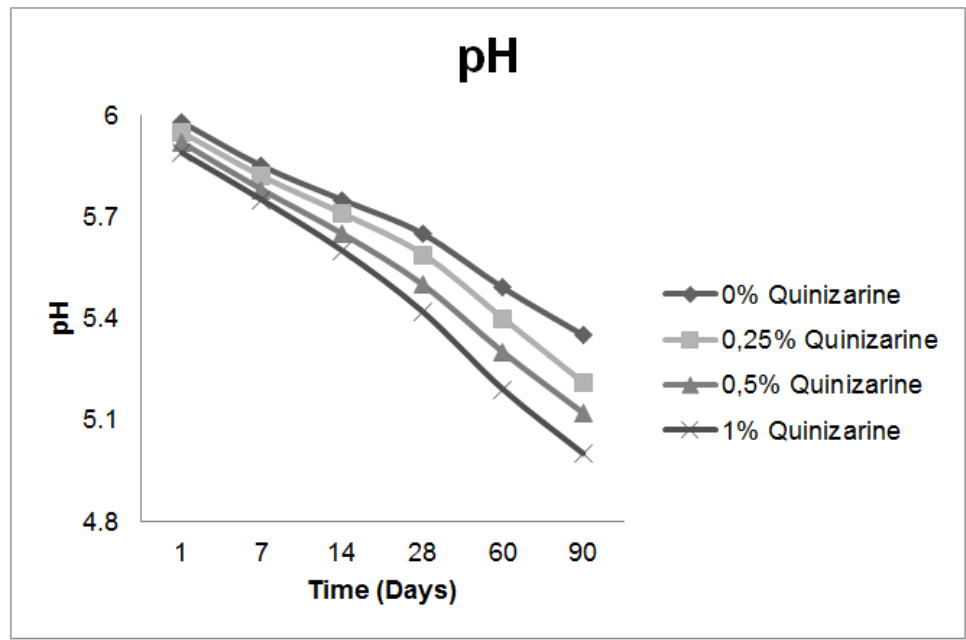

Fig-4: Effect of storage time on pH for Disperse Blue 60 inks with and without the active agent

\section{Conductivity Measurement}

Figure-3 shows the effect of storage time on the conductivity of the blue inks. It can be seen that the presence of antifraud marker in all cases causes an increase in conductivity values compared to the reference formulations. This can be attributed to the 
presence of ionized phenolic hydroxyl groups of quinizarin which may give rise to higher conductivity values compared to the reference blue ink. Conductivity values are also proportional to the quantity of the agent used in both dye inks prepared.

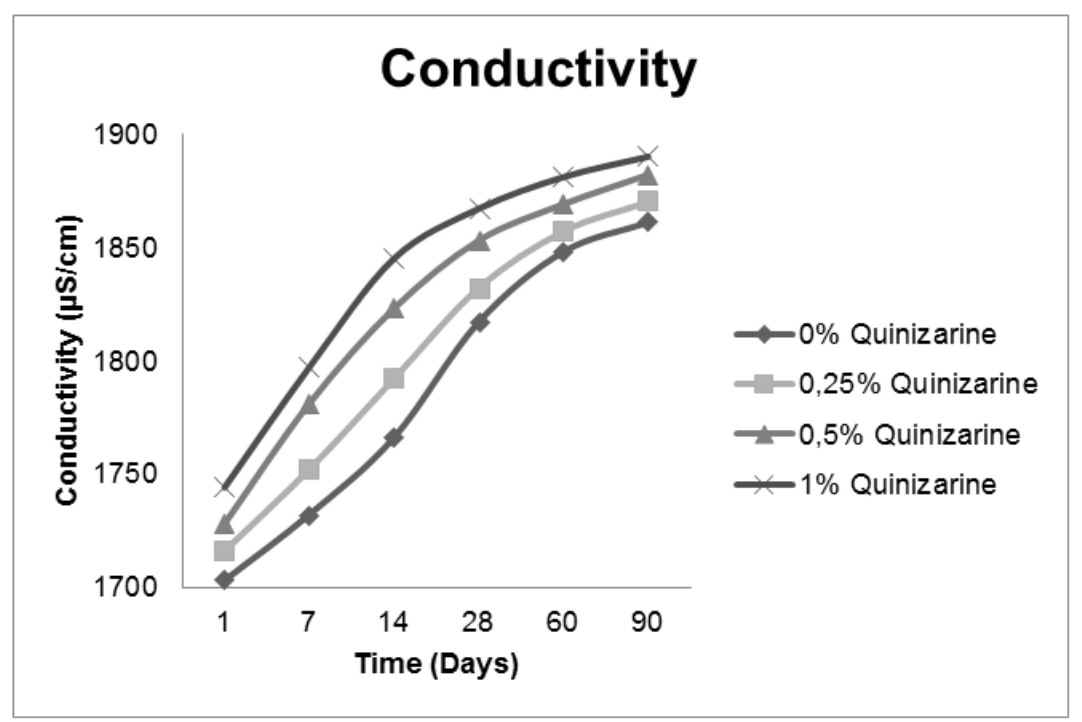

Fig-5: Effect of storage time on the conductivity of Disperse Blue 60 inks with and without the active agent

\section{Surface Tension Measurement}

Figure- 6 shows the surface tension values of a small increase during the storage time. It is widely accepted that typical surface tension values of commercial ink-jet inks for textile printing are in the range $21-48$ or $30-60 \mathrm{mNm}^{-1}[14,15]$. All inks prepared have surface tension values within the proposed ranges. The stability of the surface tension over a period of 90 days shows that all inks prepared are suitable to be used as ink-jet inks. The addition of tracer does not influence the surface tension and despite a slight increase surface tension values lie within the acceptable limits. This slight increase in surface tension can be attributed to the higher surface activity conferred by the phenolic hydroxyl groups with the hydrophobic character. When surface tension increases is a benefit for the adhesional wetting of the ink.

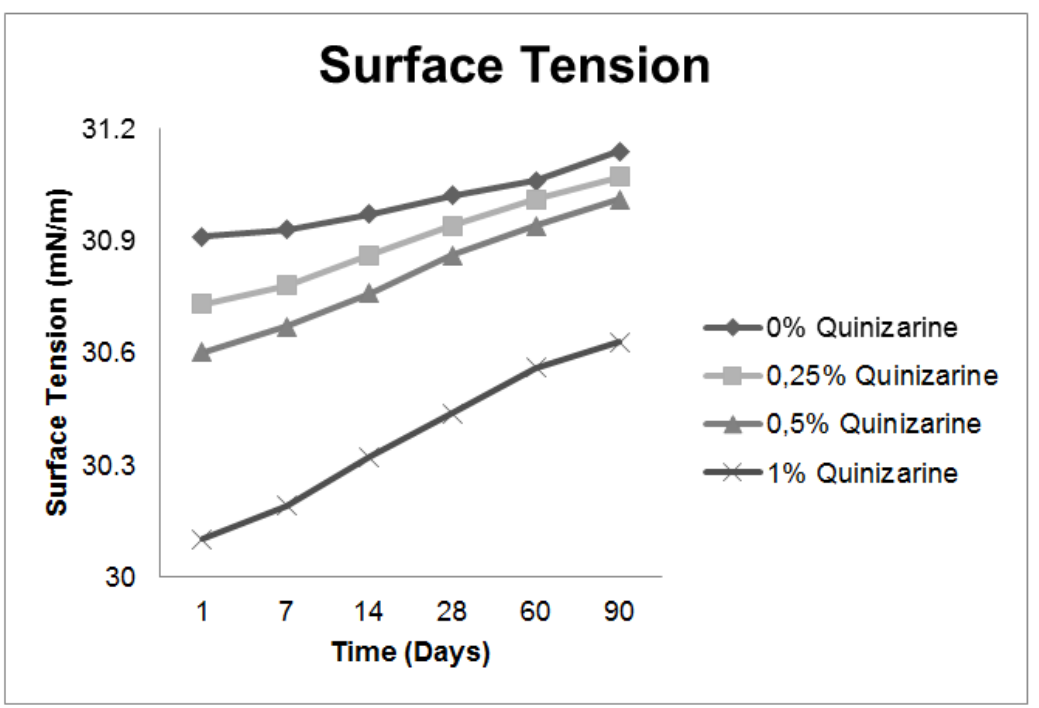

Fig-6: Effect of storage time on the surface tension of Disperse Blue 60 inks with and without the active agent

\section{Viscosity Measurement}

Figure-7 shows the effect of storage time on viscosity. It is generally accepted that ink jet inks should have a viscosity lower than $2 \mathrm{cP}$ to be suitable for digital printing application although it is not unknown for such inks to have a viscosity up to $3 \mathrm{cP}$ [14-15]. Both blue inks with and without the active agent showed a slightly increase in viscosity followed by a sharp increase in viscosity after about 28 days of storage. This sharp increase in viscosity can be attributed to the presence of the dispersing agent, Alcosperse LFD, which is a sodium salt of a polysulphonated derivative full dissociation of which produce more anionic repulsions and thus causing an increment in viscosity 
during the storage time. All prepared inks with and without the active agents show acceptable viscosity values up to 28 days of storage for ink jet ink applications for digital printing [16]. Finally the inks which contain the antifraud marker have upper viscosity values due to the presence of ionized phenolic hydroxyl groups of quinizarin which may give rise to higher viscosity values compared to the reference blue ink.

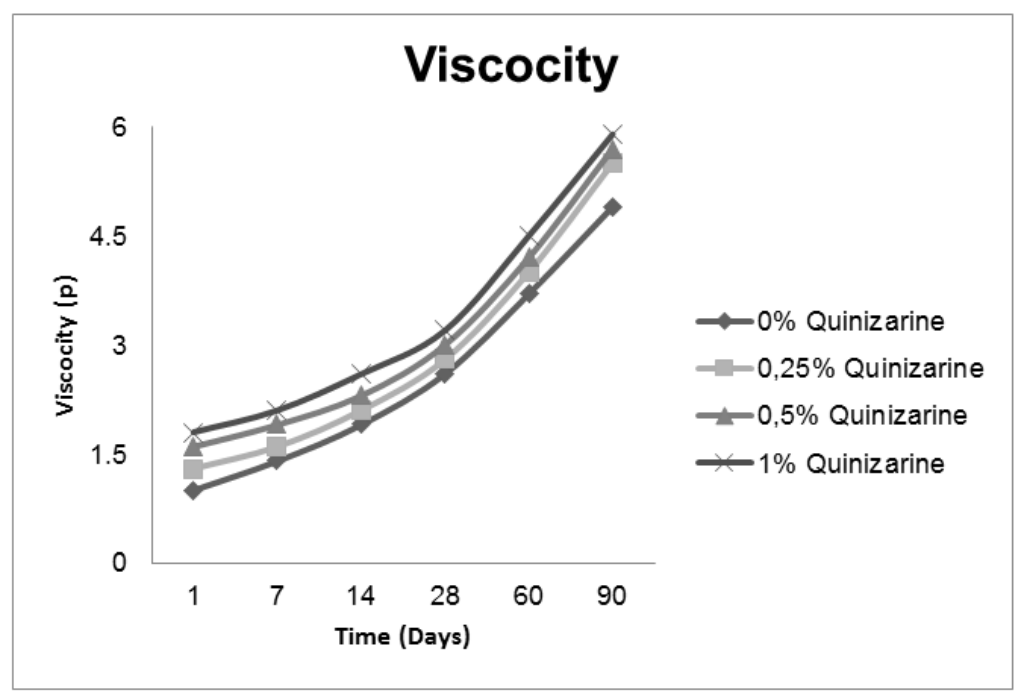

Fig-7: Effect of storage time on the viscosity of Disperse Blue 60 inks with and without the active agent

Ink-jet printing of polyester and polyamide fabrics Fastness properties of the prints

Tables 2 \& 3 show the fastness and color properties of the ink jet inks applied to polyester and polyamide after a storage period of 90 days with and without the inclusion of the tracer.

Table-2: Fastness properties of the printed samples

\begin{tabular}{|c|c|c|c|c|c|c|c|c|c|c|c|}
\hline \multirow[t]{2}{*}{ Sample } & \multirow[t]{2}{*}{ Fibre } & \multirow[t]{2}{*}{$\begin{array}{l}\text { Colour } \\
\text { Change }\end{array}$} & \multicolumn{6}{|c|}{ Wash Fastness } & \multirow[t]{2}{*}{$\begin{array}{l}\text { Light } \\
\text { Fastness }\end{array}$} & \multicolumn{2}{|c|}{$\begin{array}{l}\text { Rub } \\
\text { Fastness }\end{array}$} \\
\hline & & & Acetate & Cotton & Nylon & Polyester & Acrylic & Wool & & Dry & Wet \\
\hline 1.1 & PES & 5 & 5 & 5 & 5 & 5 & 5 & 5 & $4-5$ & 5 & 5 \\
\hline 1.2 & PES & 5 & 5 & 5 & 5 & 5 & 5 & 5 & $4-5$ & 5 & 5 \\
\hline 1.3 & PES & 5 & 5 & 5 & 5 & 5 & 5 & 5 & $4-5$ & 5 & 5 \\
\hline 1.4 & PES & 5 & 5 & 5 & 5 & 5 & 5 & 5 & $4-5$ & 5 & 5 \\
\hline 1.1 & $\mathrm{PA}$ & 5 & 5 & 5 & 5 & 5 & 5 & 5 & 2 & 5 & 5 \\
\hline 1.2 & PA & 5 & 5 & 5 & 5 & 5 & 5 & 5 & 2 & 5 & 5 \\
\hline 1.3 & PA & 5 & 5 & 5 & 5 & 5 & 5 & 5 & 2 & 5 & 5 \\
\hline 1.4 & $\mathrm{PA}$ & 5 & 5 & 5 & 5 & 5 & 5 & 5 & 2 & 5 & 5 \\
\hline
\end{tabular}

Table-2 shows that addition of Quinizarin does not affect the light fastness properties of the polyester and polyamide prints and this confirms the fact that the active agents show good compatibility with the dyes and the other ingredients of the ink formulations. All prints on polyester fabric for both inks with or without the inclusion of the active agent present average light fastness (4-5 on blue scale, Table-2) and excellent wash fastness ( 5 on grey scale) for both color change and staining of the adjacent fibres. Rub fastness both wet and dry were excellent, (5 on grey scale) for both polyester printed samples with and without active agent.

On polyamide application wash fastness was excellent (5 on grey scale), as in the case of polyester application, for both ink-jet inks with or without the inclusion of the active agent. Rub fastness both wet and dry were excellent, ( 5 on grey scale) for all polyamide printed samples. However, the light fastness on polyamide were low ( 2 on blue scale). It is well known that disperse dyes are mainly used for the dyeing and printing of polyester fibres and to a lesser extent for the dyeing and printing of nylon where they show moderate build up and fastness properties [16]. These results are in agreement with previous experimental findings for the same dyes and can be attributed to their structural features in connection to the substrate [17]. Once again the inclusion of the active agents does not affect the light fastness of the polyamide prints.

\section{Color Measurement}

Table-3, shows the color coordinates $\mathrm{L}^{*}, \mathrm{a}^{*}$, $b^{*}, C^{*}, H^{*}$ and the color strength, K/S values, of the polyester and polyamide prints with and without the inclusion of the active agent. A significant increase in the K/S values for all blue ink-jet ink has been observed 
on polyester application with the inclusion of the active agents. It seems that the agent has a "carrier action" on polyester application [18]. On polyamide application the inclusion of the active agent seems to have the same effect as on polyester. The color strength of the polyamide prints are much lower compared to polyester ones and this can be explained that disperse dyes are used especially for polyester dyeing and printing of where they show good build up and a lesser extent for polyamide application [16].

Table-3: Colorimetric data of the dyed samples

\begin{tabular}{|l|l|l|l|l|l|l|l|l|}
\hline Sample & Fibre & $\boldsymbol{\lambda} \mathbf{m a x}$ & $\mathbf{K} / \mathbf{S}$ & $\mathbf{L}^{*}$ & $\mathbf{a}^{*}$ & $\mathbf{b}^{*}$ & $\mathbf{C}^{*}$ & $\mathbf{h}^{\mathbf{0}}$ \\
\hline 1.1 & PES & $680 \mathrm{~nm}$ & 0.255 & 83.45 & -7.77 & -5.91 & 9.76 & 217.25 \\
\hline 1.2 & PES & $680 \mathrm{~nm}$ & 0.32 & 82.44 & -9.49 & -7.81 & 12.29 & 219.45 \\
\hline 1.3 & PES & $680 \mathrm{~nm}$ & 0.353 & 82.16 & -10.36 & -8.66 & 13.50 & 219.22 \\
\hline 1.4 & PES & $680 \mathrm{~nm}$ & 0.379 & 81.45 & -10.62 & -9.11 & 13.99 & 220.61 \\
\hline 1.1 & PA & $680 \mathrm{~nm}$ & 0.145 & 82.54 & -1.76 & 0.18 & 1.77 & 174.27 \\
\hline 1.2 & PA & $680 \mathrm{~nm}$ & 0.169 & 82.56 & -3.38 & -1 & 3.52 & 196.45 \\
\hline 1.3 & PA & $680 \mathrm{~nm}$ & 0.175 & 81.83 & -2.98 & -0.79 & 3.09 & 194.86 \\
\hline 1.4 & PA & $680 \mathrm{~nm}$ & 0.189 & 81.56 & -3.28 & -0.94 & 3.42 & 196 \\
\hline
\end{tabular}

With negative $\mathrm{a}^{*}$ and $\mathrm{b}^{*}$ values and $\mathrm{h}^{\mathrm{o}}=174.27-220.61^{\circ}$ the blue polyester and polyamide printings lie in the blue-green sector of the color circle.

\section{Identification and quantitative determination of the active agents adsorbed on printed polyester and polyamide sample}

The effect of Quinizarin on the thermofixed fabric was evident since effect of the printed fabric was able to be seen by bare eye on suitable light cabinet conditions. This result could be related to the property of the active agent to increase the surface tension of the corresponding inks (Figure 6). Since printing involves superficial adhesion of the ink on the fabric and not penetration in the fibre (dyeing) this surface tension increase is at the benefit of the adhesional wetting of the ink [19]. Similar results were obtained with the addition of other active agents in the digital printing inks such as antimicrobials which from the same water system "transferred" to the substrate (PES, PA) with the same application method paper to fabric (unpublished results). It is believed that the transfer of the ink from the paper to the textile substrate is being made not through a conventional sublimation transfer mechanism but through a melt or wet transfer mechanism. Almost $100 \%$ transfer of the printed ink from the paper to the textile substrate is taking place under the transfer conditions employed.

Quantitative determination of the tracer Quinizarin included in the ink-jet ink formulation was performed. The quantitative determination was made on the printed samples after extraction of the active agent with a mixture of cresol/heavy naftha $50 / 50 \mathrm{v} / \mathrm{v}$ and measuring spectrophotometrically the extract at $483.5 \mathrm{~nm}$ ( $\lambda \max$ of Quinizarin). Table-4 summarize the results obtained for polyester and polyamide samples printed with various amounts of the active agent.

Table-4: Amount (mg/L) of Quinizarine extracted from polyester (PES) and polyamide (PA) printed samples

\begin{tabular}{|l|l|l|l|}
\hline \multicolumn{2}{|l|}{ POLYESTER } & \multicolumn{2}{l|}{ POLYAMIDE } \\
\hline Sample & Amount mg/L & Sample & Amount mg/L \\
\hline 1.2 & 20.69 & 1.2 & 16.48 \\
\hline 1.3 & 38.58 & 1.3 & 29.81 \\
\hline 1.4 & 73.26 & 1.4 & 66.37 \\
\hline
\end{tabular}

The desorption of active agents is generally more for the higher application levels of the active agents but not proportionally. It seems that an application level of $0.25 \%$ in the ink-jet ink printing formulation is enough and can easily be detected in the solution after extraction with a mixture of cresol/heavy naftha at room temperature for 30 minutes as it was described in the experimental section. The above results indicate that Quinizarine can be used in the ink-jet ink printing formulation as "marker" to distinguish for example between the original and imitation articles.

\section{Conclusions}

The use of Quinizarin as active agent in the formulation of ink-jet inks for digital printing has been studied. The active agent can be used as "marker" in the printing paste in order to detect original from counterfeit products.

A simple spectrophotometrical method is described which allows an easy and accurate detection of the active agent and thus allows the use of active agent as antifraud marker. The above method provides a simple and on the spot quick, reliable and inexpensive laboratory method for distinguishing the counterfeit products. 


\section{ACKNOWLEDGEMENTS}

This research is co-financed by Greece and the European Union (European Social Fund- ESF) through the Operational Programme «Human Resources Development, Education and Lifelong Learning» in the context of the project "Reinforcement of Postdoctoral Researchers - 2nd Cycle" (MIS-5033021), implemented by the State Scholarships Foundation (IKY).

\section{REFERENCES}

1. Fryberg, M. (2005). Dyes for ink-jet printing. Review Progress Coloration. 35(1), 1-30.

2. Daplin, S., \& Lin, L. (2003). Evaluation of pigmented ink formulations for jet printing onto textile fabrics. Pigment and Resin Technology. 32(5), 307-318.

3. Holme, I. (2004). Digital ink jet printing of textiles. Textile Magazine. 1, 11-16.

4. Kang, H. R. (1991). Water based ink jet ink. II. Characterization. Journal Imaging Science Technology. 35, 189-194.

5. Yamanoto, T., Haruta, M., Koike, S., Shirota, K., Yoshihira, A., \& Suzuki M. (1997). Textile printing method, printed textile obtained thereby, and ink SI Patent, no. 8910720.

6. Dawson, T. L. (2006). Digital Printing of Textiles. Woodhead Publishing, Campridge.

7. Nicoll, L. (2006). Digital Printing of Textiles. Woodhead Publishing, Campridge.

8. Cahill, V., \& Ujiie, H. (2004). Digital Textile Printing 2004. IS \& T NIP 20, Salt Lake City, UT.
9. Provost, J. R. (1995). Dynamic Response in Textile Printing, Textile Chemist \& Colorist. 27(6), 11.

10. Derksen, G. C. H., Niederlander, H. A. G., \& Van Beek, T. A. (2002). Analysis of anthraquinones in Rubia tinctorum L. by liquid chromatography coupled with diode-array UV and mass spectrometric detection, Journal Chromatography A. 978 (1-2), 119-127.

11. Bien, H-S, Stawitz, J. \& Wunderlich, K. (2000). Anthraquinone Dyes and Intermediates. WileyVCH Weinheim, Germany: Ullmann's Encyclopedia of Industrial Chemistry.

12. Methods of Test for Colour Fastness of Textiles and Leather. (1990). Bradford: Society of Dyers and Colourists.

13. Kang, H. R. (1991). Journal Imaging Science Technology. 35, 189-201.

14. Schulz, G. (2003). Melliand Textilberichte. 83, 154.

15. Siemensmeyer, K., \& Dorer, M. (1993). Melliand Textilberichte. 79, 867.

16. Burkinshaw, S. M. (1995). Chemical Principles of Synthetic Fibre Dyeing. Chapman \& Hall, London, UK.

17. Broadbent, A. D. (2001). The basic principles of textile coloration. Dyers Company Publication, West Yorkshire.

18. Iskender, M. A., Bacevir, B., \& Kurujucu, A. (2005).Carrier Dyeing of Different Energy Level Disperse Dyes on Polyester Fabric. Textile Research Journal. 75(6), 462-465.

19. Myers, D. (1988). Surfactant Science and Technology. VCH Pub, New York. 